\title{
Correlation and Predictive Relationship between Self-determination Instruction and Academic Performance of Students with Disabilities
}

\author{
Pen-Chiang Chao", Yu-Chi Chou \\ College of Humanities and Education, Department of Special Education Faculty, Chung Yuan Christian University, Taiwan
}

Copyright@2017 by authors, all rights reserved. Authors agree that this article remains permanently open access under the terms of the Creative Commons Attribution License 4.0 International License

\begin{abstract}
The purpose of this study was to investigate the correlation and probable predictive relationship between self-determination skills taught by special education teachers and the academic performance of students with disabilities from junior high schools in Taiwan. The subjects included teachers from resource rooms and self-contained classrooms ( $n=106)$ and students with disabilities in these classes ( $n=106)$. Two measures, the Teaching Self-determination Scale (TSDS) and the Basic Learning Competency Assessment (BLCA), were used to collect data. The Pearson correlation, bivariate linear regression and stepwise multiple regression analyses were used to assess the correlation and predictive relationship between the TSDS and BLCA. Findings showed a positive correlation between self-determination instruction given by special education teachers and the academic performance of students with disabilities. Educators' self-determination instruction was found to be able to explain $26 \%$ of the total variance of students' academic performance. Furthermore, teaching psychological empowerment and autonomy skills appeared to be able to best predict the academic performance of students with disabilities. The two variables were found to be able to explain $21.9 \%$ of the total variance of the students' academic test results. Suggestions and implications are provided.
\end{abstract}

Keywords Academic Performance, Self-determination, Special Education Teachers, Students with Disabilities

\section{Introduction}

Recently, there has been an increase in the number of studies related to the self-determination of students with disabilities. Topics such as the exploration of the definition of self-determination and construction of corresponding theories, composition of ability assessment instruments, and development of teaching courses have received growing attention from scholars and practitioners in the field of education. One reason for this trend could be attributed to the lack of self-determination among students with disabilities [25]. Compared to students without disabilities, the level of self-determination of students with disabilities is found to be significantly lower [27]. In addition to influencing the quality of life of these students at home, in schools, and in local communities [20], the lack of self-determination may also lead to difficulties in future academic transitions and upgrades, as well as in job seeking processes [29]. Fortunately, research has confirmed that self-determination is an ability that can be acquired through learning [1, 16, 21]. If teachers can design and teach corresponding courses based on the abilities and demands of students with disabilities, their potential to obtain self-determination that is related to knowledge and skills can be developed. On that account, teachers play an essential role in the development of self-determination among students with disabilities.

During the past 20 years, many studies have investigated the effects of self-determination training on the improvement of self-determination among students with disabilities [16, 21, 22]. However, recent trends have begun placing more emphasis on the correlation between self-determination training and the academic performance of students with disabilities [11]. Such a shift in research can be attributed to the following reasons: First, self- determination is considered to be one of the core abilities for effective learning. For example, being able to understand oneself can help learners choose the most suitable learning strategy for them, while self-regulation skills are conducive to the planning of learning processes and content. Second, from the motivation perspective, both self-determination and learning behavior share a common ground on emphasizing the importance of individuals' intrinsic motivation. Murray and Wren [18] pointed out that learning behavior founded upon intrinsic motivation could lead to the best outcomes. Deci and Ryan [8] also advocated that behavior that is driven by intrinsic 
motivation can be considered as a self-determination behavior. Hence, it can be concluded that learning behavior and self-determination are closely associated.

In addition, the performance of students with disabilities after graduating from schools has been found to be worse than expected. In particular, when compared to their typically developing peers, students with disabilities tend to have worse performance in learning specialized subjects, which substantially reduces their likelihood of upgrading to higher education and successfully finding a job. For that reason, academia has called attention to improving the academic performance of these students so that they may have a smooth transition and sufficient competencies in the labor market [2, 3]. One of the key influencing factors of a successful transition of students is self-determination [5, 19, 24]. Thus, it can be induced that academic performance and self-determination are positively correlated. In fact, according to a report of the National Longitudinal Transition Study-2 (NLTS2) funded by the US Department of Education, the self-determination and academic performance of high-school students with intellectual disabilities have a significant, positive correlation [31]. In addition, scholars have also pointed out that teaching self-determination skills to students with disabilities can effectively improve their academic performance and reduce the likelihood of them dropping out of school [30].

In summary, there is a close association between self-determination and academic performance of students with disabilities. International studies have also confirmed that self-determination and academic performance of students with disabilities are closely related. Regardless of the type of disabilities, such as learning disabilities [17,31], intellectual disabilities \& autism [10,11], and multiple disabilities [4], students with a higher degree of selfdetermination tend to have better academic performance, whereas the academic performance of students with a lower degree of self-determination is likely to be poorer.

Moreover, in the past ten years, more research has focused on the relationship between self-determination training and academic performance of students with disabilities. Copeland and Hughes [7] applied a meta-analysis method to explore the impact of teaching goal-setting skills on task performance of individuals with intellectual disabilities (with ages ranging from primary school students to middle-aged adults). Using a primary school student with Down syndrome and mild intellectual disability as a research subject, Brooks et al. [4] examined the relationship between being trained in self-management skills and the improvement in on-task behavior and assignment completion. Hughes et al. [13] explored the effectiveness of teaching self-monitoring skills to four high school students with mental retardation on improving learning efficiency in an occupational health class. Rock [23] investigated the effects of teaching self-monitoring skills on the mathematics performance of nine primary school students with learning disabilities, emotional/behavioral disorders, and Asperger syndrome.
Adopting a meta- analysis method, Konrad et al. [17] explored the effectiveness of teaching self-determination skills on the academic performance of students with intellectual disabilities from primary school to undergraduate level. Fowler et al. [10] adopted a meta-analysis approach and investigated the impact of self-determination training on improving the academic achievement of students with cognitive disabilities. All the aforementioned studies found that teaching self-determination skills is beneficial to the academic performance of students with disabilities. However, whether this conclusion is also applicable to students with disabilities in Taiwan remains unclear. Since there is limited research focusing on this topic in Taiwan, the correlation and causal relationships between self-determination training and academic performance of students with disabilities has yet to be determined.

The purpose of this study was to investigate the correlation and probable predictive relationship between self-determination skills taught by special education teachers and the academic performance of students with disabilities from junior high schools in Taiwan. Junior high school is a critical stage for the development of students' self-concept, self-initiative, and problem-solving skills [26]. Students with disabilities that would like to continue to senior high schools still need to participate in various academic competency tests. For example, students with intellectual disabilities are required to participate in the national Basic Learning Competency Assessment (BLCA), the results of this test are used as a reference in their assessment by vocational high schools or special education schools. Therefore, this study selected special education teachers and students from junior high schools as research subjects.

\section{Method}

\subsection{Participants}

The subjects of this study included teachers from resource rooms and self-contained classrooms $(n=106)$ and students with disabilities in these classes $(n=106)$. A random sampling method was applied to select teachers from public junior high schools in Taiwan. Then, each teacher was asked to choose one student from his/her class to participate in the study. Among the selected teachers, 71 taught in resource rooms and 35 taught in self-contained classrooms. There were more female $(n=82)$ than male teachers $(n=24)$. This proportion is in line with the proportion of female and male teachers in junior high schools in Taiwan. The age of the teachers was between 24 to 56 years old $(M=39.3)$. The teaching experience of the teachers ranged from 2 to 33 years $(M=15.2)$. The number of male and female students was 55 and 51, respectively. All the students were in grade 9. Among the student participants, 71 received special education services from resource rooms due to mild intellectual disability $(n=59)$ and autism $(n=12)$. The 
remaining 35 students included 27 with moderate intellectual disability and 8 with multiple disabilities, educated in self-contained classrooms. The reason that only students from grade 9 were included in the study was due to the use of the assessment tool (BLCA), which was only applicable for students at this educational level.

\subsection{Measures}

The Teaching Self-Determination Scale (TSDS; Chao \& Chou, 2016) was used to collect data in this study. This measure was developed to examine the extent to which Taiwanese elementary and junior high school educators teach students knowledge and skills related to self-determination. The conceptual framework of the TSDS is based on a functional model of self-determination proposed by Wehmeyer [28]. It can be administered to both general and special education teachers. The 24-item scale is comprised of four sub-scales: self-realization (SR), psychological empowerment (PE), self-regulation (SG), and autonomy (AT). The participants' responses were scored on a 5 -point Likert-type scale $(1=$ never, $2=$ rarely, $3=$ sometimes, $4=$ often, $5=$ always). The overall composite score, known as the "Full Scale" for the TSDS, ranged from 24 to 120. A higher score refers to a greater frequency of instruction in skills related to self-determination. The SR sub-scale included five statements measuring the extent to which teachers provide instruction in self-observation, self-awareness, and self-knowledge. The PE sub-scale contained six statements assessing the degree to which teachers educate or empower students to build a positive belief regarding their own ability, maintaining an internal locus of control, and the expectation of success. The SG domain consisted of five descriptions asking teachers to evaluate the extent to which they teach students problem solving and goal setting skills. The AT sub-scale comprised eight statements evaluating the extent to which teachers provide instruction in self-management, personal care, engagement in recreational activities, and independent living skills. The statistical adequacy of the TSDS was computed based on 203 educators participating in a pilot study. Results showed that the internal consistency reliability coefficients (Cronbach's $\alpha$ ) for the sub-scales ranged from .76 to .88, while the test-retest reliability coefficients ranged from .78 to .85 . For the Full Scale, the coefficients were .93 and .89 , respectively.

The Basic Learning Competency Assessment (BLCA) test was compiled by the Ministry of Education in Taiwan. The main purpose of the BLCA is to assess the basic learning competencies of grade 9 students with disabilities. The results of the test are used to determine whether the students are fit to enter vocational high schools or special education schools. The BLCA mainly targets students with mild and moderate intellectual disabilities, autism, and multiple disabilities. The content of the BLCA cover academic competencies and vocational skills. A pencil-and-paper test is used to assess academic competencies, and a practical test is adopted to assess vocational skills. In this study, the students' academic performance was referred to the results of the test of academic competencies. The subjects included in the academic test were Chinese, English, Mathematics, and Sociology. The coverage of each subject was restricted to knowledge taught in junior high schools. The test comprised all multiple-choice questions, and students were requested to choose one correct answer, or the best answer among the four choices for each question. Each question accounted for 2 points. The total points (BLCA score) that a student could acquire ranged from 0 to 50 . The higher the BLCA score, the better the student's academic competencies.

\subsection{Procedures}

Research assistants reviewed a list of public junior high schools nationwide in Taiwan, and randomly selected potential participating schools. The assistants, then, contacted the director of academic affairs at each of the chosen schools by phone and asked for permission to include their schools in the study. Surveys and consent forms were then mailed to the directors who had agreed to participate. The directors were asked to distribute the surveys to potential participating teachers. The teachers who were willing to participate in the study were then asked to randomly select one of their students as candidates for the study. After receiving consent from the parents of the students, the students were then asked to complete the BLCA.

\subsection{Data Analysis}

The study first used the Pearson correlation analysis to assess the linear relationship between the TSDS and BLCA. Correlation coefficients were computed between each of the five TSDS scales (i.e., four subscales and full scale) and the five BLCA scores (i.e., four subjects' score and total score). The significant correlation analysis between the TSDS full scale and BLCA total score was followed by conducting a bivariate linear regression analysis to evaluate the prediction of BLCA total score from TSDS full scale. Furthermore, a stepwise multiple regression analysis was conducted to evaluate how well the four TSDS subscales predicted the BLCA total score.

\section{Results}

The results of the Pearson correlation analysis showed that each of the ratings given by the teachers to the TSDS and its sub-scales were all positively correlated to the students' BLCA score in each subject $(p<.05)$ (Table 1). The correlation coefficients $r$ ranged between .20 and .51. As is shown in Table 1, the correlations between the Full Scale of the TSDS and students' performance in the Chinese and English tests were relatively high $(r=.45$ and .46 respectively), while the correlation between the Full Scale of the TSDS and students' performance in the Mathematics test 
was relatively low $(r=.28)$. The Full Scale of the TSDS scale and the students total BLCA score were found to have the greatest correlation $(r=.51)$. In addition, the correlations between the rating of each sub-scale of the TSDS and the scores in the Chinese, English, and Sociology tests were found to be relatively high, whereas the correlation between each sub-scale of the TSDS and the Mathematics score appeared to be relatively low.

Given that the results of the correlation analysis were statistically significant, we further applied a regression analysis to assess the predictive power of self-determination instruction on students' academic performance. A bivariate regression analysis showed that the Full Scale of the TSDS was able to effectively predict students' BLCA results $\left(F_{(1,104)}=36.48, p<.01, R^{2}=.26\right)$, by explaining $26 \%$ of the total variance.

Then, a stepwise multiple regression analysis was applied, by introducing the ratings of the four sub-scales into the model simultaneously, revealing that only the ratings of psychological empowerment $(t=2.25, p=.027)$, autonomy $(t=3.05, p=.003)$ and students' total BLCA score were significantly correlated. Since the correlation between autonomy and the BLCA score was relatively high, a second round of regression analysis was conducted, and autonomy rating was introduced into the model prior to introducing psychological empowerment rating. The results are presented in Table 2. As is shown in the table, the results of both regression steps were statistically significant. When only autonomy was introduced in the model, the model could explain $13.0 \%$ of the total variance of the BLCA score. After introducing psychological empowerment, the two variables were found to be able to explain $21.9 \%$ of the total variance of the BLCA score $\left(\Delta R^{2}=9.5 \%\right)$

\section{Discussion}

The results of this study showed a positive correlation between self-determination instruction delivered by special education teachers and the academic performance of students with disabilities, which is consistent with findings of past research $[10,11,13,17,31]$. The students who participated in this study were quite diverse, including students with mild to moderate intellectual disabilities, autism, and multiple disabilities and were selected from varied settings, from resource rooms to self-contained classrooms. Therefore, it can be suggested that teaching self-determination skills is likely to be positively correlated with the academic performance of junior high school students with different types of disabilities. However, the probable interactive effect between disability type, degree of disability, teaching performance, and students' academic performance cannot be excluded; therefore, further studies are required to explore this aspect further.

In this study, the Full Scale of the TSDS and the ratings of its sub-scales were found to be significantly correlated with students' BLCA scores. The correlation between the Full Scale of the TSDS and the total BLCA score was found to have the greatest coefficient $(r=.51)$. In addition, the correlation coefficient between the rating of autonomy and the total BLCA score was also high $(r=.50)$. Scholars have suggested that a correlation coefficient greater than .50 indicates a strong correlation between two variables [12]. The correlation coefficients between students' performance in the Chinese, English, and Sociology tests and the Full Scale of TSDS as well as ratings of the sub-scales attained a moderate level $(r=.30)$, whereas the determined correlation between students' mathematics test results and self-determination instruction provided by teachers was between weak to moderate. One possible explanation for this difference could be that Mathematics is focused on logical thinking and calculation ability with little relevance for life skills, such as self-determination. Future studies are recommended to further verify this assumption.

Table 1. Bivariate Correlations between the TSDS and BLCA Variables

\begin{tabular}{|c|c|c|c|c|c|}
\hline Variable & Chinese & English & Mathematics & Sociology & $\begin{array}{c}\text { BLCA } \\
\text { Total Score }\end{array}$ \\
\hline Self-Realization & $.34^{* *}$ & $.33^{* *}$ & $.20^{*}$ & $.30^{* *}$ & $.36^{* *}$ \\
\hline Psychological Empowerment & $.42^{* *}$ & $.45^{* *}$ & $.26^{* *}$ & $.34^{* *}$ & $.47^{* *}$ \\
\hline Self-Regulation & $.34^{* *}$ & $.37^{* *}$ & $.20^{*}$ & $.30^{* *}$ & $.37^{* *}$ \\
\hline Autonomy & $.49^{* *}$ & $.42^{* *}$ & $.28^{* *}$ & $.42^{* *}$ & $.50^{* *}$ \\
\hline TSDS Full Scale & $.45^{* *}$ & $.46^{* *}$ & $.28^{* *}$ & $.39^{* *}$ & $.51^{* *}$ \\
\hline
\end{tabular}

${ }^{*} p<.05, * * p<.01$

Table 2. Summary for the Stepwise Regression Analysis

\begin{tabular}{|c|c|c|c|c|c|c|c|}
\hline \multicolumn{2}{|c|}{ Model/Variable } & $R$ & $R^{2}$ & $R_{\text {adj }}^{2}$ & $\Delta R^{2}$ & $F$ & $\Delta F$ \\
\hline 1 & Autonomy & .372 & .138 & .130 & .138 & $16.70^{* *}$ & $16.70^{* *}$ \\
\hline \multirow{2}{*}{2} & Autonomy & .483 & .234 & .219 & .095 & $15.71^{* *}$ & $12.81^{*}$ \\
\cline { 2 - 7 } & Psychological Empowerment & & & & & \\
\hline
\end{tabular}

${ }^{*} p<.05,{ }^{* *} p<.01$ 
Previous scholars have pointed out that self- determination is a complex concept that covers various types of abilities, including choice making, decision-making, problem-solving, goal-setting and attainment, self-advocacy, and internal locus of control [28]. These abilities can help students design study plans, set learning objectives, manage study time, choose learning strategies, and apply self-reflection and revision [9]. For that reason, the more self-determination related skills are taught by teachers, the more likely the students are to achieve good academic performance. The results of our regression analyses support this statement. Specifically, the Full Scale of the TSDS was found to be able to explain $26 \%$ of the total variance of the students' BLCA test results.

Furthermore, teaching psychological empowerment and autonomy skills appeared to be able to effectively predict the academic performance of students with disabilities. The two variables were found to be able to explain $21.9 \%$ of the total variance of the students' academic test results. This finding puts forward two important revelations. First, teaching students the ability to be autonomous is the most effective predicting factor for students' academic performance, indicating that autonomy related skills, such as self-monitoring, self-management, and problem solving have a significant impact on students' academic achievements [9]. Second, although the psychological empowerment of students with disabilities is challenging to measure, it is a key influencing factor in the effectiveness of learning. However, psychological empowerment and self-initiative abilities are some of the most overlooked skills by special education teachers [5]. The labels people tend to associate with the population with disabilities, and the corresponding stigmatization, have led to significant damage to self-esteem, self-confidence, and self-affirmation. The labels that people have given to the students with mild to moderate intellectual disabilities, autism, and multiple disabilities in our study have also been found to have caused a negative impact on their psychological empowerment [14, 15]. For that reason, in order to enhance the academic performance of these students, strengthening their psychological empowerment is also of great significance. In summary, cultivating self-determination skills from cognitive (psychological empowerment) and practical (autonomy) perspectives are equally important. Training students in self-affirmation skills, maintaining positive and optimistic attitudes towards the learning outcomes, and guiding students to achieve learning objectives through autonomous learning and problem solving are both effective predictors for the academic performance of students with disabilities.

\section{Conclusions}

The results of this study re-affirm that positive correlations exist between self-determination training and the academic performance of students with physical and mental disabilities. In addition, teaching students self-determination skills is an effective predictor of their learning outcomes. However, because the TSDS is a self-reported scale, the information collected is likely to be distorted by the subjective judgment and assessment of the teachers. Since discrepancies may exist between actual teaching practice and teachers' self-assessed teaching content, caution should be taken when applying the findings of this study to interpreting the relationship between teaching self-determination and student performance. Furthermore, there may be mediating variables between teachers' self-determination instruction and students' academic performance. Hence, over simplifying the relationship between the two variables is not suggested. Based on the results of this study, the following recommendations are proposed as references for researchers and practitioners. First, future research is recommended to adopt more diversified approaches, to assess the extent of self- determination instruction that teachers provide to supplement the limitations of the self-reported approach, such as collecting feedback from students and their parents. Second, the correlations and predictive relationships between self-determination instruction and students' academic performance are limited to students that are eligible to participate in the BLCA. Whether the findings can be applied to students with other types of disabilities, particularly those with learning disabilities or sensory impairments is unclear and awaits further investigation. Lastly, the results of this study have highlighted a strong correlation between self-determination instruction and students' academic performance. Academic competencies are key factors that determine the likelihood of students with disabilities to successfully receive higher levels of education and finding a job in later life; therefore, it is suggested that special education teachers place more attention on providing self-determination instruction to students.

\section{Acknowledgements}

This study was supported by Investigation of Special Education Teachers' Self-Determination Instruction and Its Influence on the Academic Performance of Students with Disabilities Project from the Ministry of Science and Technology, Taiwan.

\section{REFERENCES}

[1] Agran, M., Cavin, M., Wehmeyer, M. L., \& Palmer, S. B. (2006). Participation of students with moderate to severe disabilities in the general curriculum: The effects of the self-determination learning model of instruction. Research and Practice for Persons with Severe Disabilities, 31, 230-241. 
[2] Benz, M. R., Lindstrom, L., \& Yovanoff, P. (2000). Improving graduation and employment outcomes of students with disabilities: Predictive factors and student perspectives. Exceptional Children, 66(4), 509-529.

[3] Brinkerhoff, L. C., McGuire, J. M., \& Shaw, S. F. (2002) Postsecondary education and transition for students with learning disabilities (2nd ed.). Austin, TX: Pro-Ed.

[4] Brooks, A., Todd, A. W., Tofflemoyer, S., \& Horner, R. H. (2003). Use of functional assessment and a self-management system to increase academic engagement and work completion. Journal of Positive Behavior Interventions, 5(3), 144-152.

[5] Carter, E. W., Lane, K. L., Pierson, M. R. \& Stang, K. K. (2008). Promoting self- determination for transition-age youth: Views of high school general and special educators. Exceptional Children, 75, 55-70.

[6] Chao, P. C., \& Chou, Y. C. (2016, September). A National Survey of Elementary and Secondary Educators' Practice in Teaching Self-Determination: Lessons Learned from Taiwan. Paper presented at the 2016 International Symposium on Education and Social Sciences (ISESS) Conference, Singapore, Republic of Singapore.

[7] Copeland, S. R., \& Hughes, C. (2002). Effects of goal setting on task performance of individuals with mental retardation. Education and Training in Mental Retardation and Developmental Disabilities, 37, 40-54.

[8] Deci, E. L., \& Ryan, R. M. (2008). Self-determination theory: A macrotheory of human motivation, development, and health. Canadian Psychology, 49, 182-185.

[9] Eisenman, L. T. (2007). Self-determination interventions: Building a foundation for school completion. Remedial and Special Education, 28, 2-8.

[10] Fowler, C. H., Konrad, M., Walker, A. R., Test, D. W., \& Wood, W. M. (2007). Self-determination intervention's effects on the academic performance of students with developmental disabilities. Education and Training in Developmental Disabilities, 42, 270-285.

[11] Gaumer-Erickson, A. S., Noonan, P. M., Zheng, C., \& Brussow, J. A. (2014). The relationship between self -determination and academic achievement for adolescents with intellectual disabilities. Research in Developmental Disabilities, 36, 45-54.

[12] Green, S. B., \& Salkind, N. J. (2011). Using SPSS for Windows and Macintosh: Analyzing and understanding data (6th ed.). Upper Saddle River, NJ: Prentice Hall.

[13] Hughes, C., Copeland, S. R., Agran, M., Wehmeyer, M. L., Rodi, M. S., \& Presley, J. A. (2002). Using self-monitoring to improve performance in general education high school classes. Education and Training in Mental Retardation and Developmental Disabilities, 37, 262-272.

[14] Jahoda, A., Wilson, A., Stalker, K., \& Cairney, A. (2010). Living with stigma and the self-perceptions of people with mild intellectual disabilities. Journal of Social Issues, 66(3), 521-534.

[15] Kauffman, J. M., \& Badar, J. (2013). How we might make special education for students with emotional or behavioral disorders less stigmatizing. Behavioral Disorders, 39(1), 16-27.
[16] Kelly, J. R., \& Shogren, K. A. (2014). The impact of teaching self-determination skills on the on-task and off-task behaviors of students with emotional and behavioral disorders. Journal of Emotional and Behavioral Disorders, 22(1), 27-40.

[17] Konrad, M., Fowler, C. H., Walker, A. R., Test, D. W., \& Wood, W. M. (2007). Effects of Self-determination interventions on the academic skills of students with learning disabilities. Learning Disabilities Quarterly, 30, 89-113.

[18] Murray, C., \& Wren, C. T. (2003). Cognitive, academic, and attitudinal predictors of the grade point averages of college students with learning disabilities. Journal of Learning Disabilities, 36(5), 407-415.

[19] Moore, M., \& McNaught, J. (2014). Virginia's selfdetermination project: Assisting students with disabilities to become college and career ready. Journal of Vocational Rehabilitation, 40(3), 247-254.

[20] Nota, L., Ferrari, L., Soresi, S., \& Wehmeyer, M. (2007). Self-determination, social abilities and the quality of life of people with intellectual disability. Journal of Intellectual Disability Research, 51, 850-865.

[21] Palmer, S. B., \& Wehmeyer, M. L. (2003). Promoting self-determination in early elementary school: Teaching self-regulated problem-solving and goal-setting skills. Remedial and Special Education, 24, 115-126.

[22] Prater, M. A., Redman, A. S., Anderson, D., \& Gibb, G. S. (2014). Teaching adolescent students with learning disabilities to self-advocate for accommodations. Intervention in School and Clinic, 49(5), 298-305.

[23] Rock, M. L. (2005). Use of strategic self-monitoring to enhance academic engagement, productivity, and accuracy of students with and without exceptionalities. Journal of Positive Behavior Interventions, 7, 3-17.

[24] Rowe, D. A., Mazzotti, V. L., \& Sinclair, J. (2015). Strategies for teaching self- determination skills in conjunction with the common core. Intervention in School and Clinic, 50(3), 131-141.

[25] Shogren, K. A., Wehmeyer, M. L., Palmer, S. B., Soukup, J. H., Little, T. D., Garner, N., \& Lawrence, M. (2007). Examining individual and ecological predictors of the self-determination of students with disabilities. Exceptional Children, 73, 488-509.

[26] Slavin, R. E. (2008). Educational psychology: Theory and practice (9th ed.). Boston: Allyn \& Bacon.

[27] Wagner, M., Newman, L., Cameto, R., Garza, N., \& Levine, P. (2005). After high school: A first look at the post-school experiences of youth with disabilities. A report from the National Longitudinal Transition Study-2 (NLTS2). Available from the National Longitudinal Transition Study-2 Website at http://www.nlts2.org/reports/2005_04 /nlts2_report_2005_04 _complete.pdf

[28] Wehmeyer, M. L. (1999). A functional model of self-determination: Describing development and implementing instruction. Focus on Autism and Other Developmental Disabilities, 14, 53-61.

[29] Wehmeyer, M. L., Palmer, S. B., Soukup, J. H. Garner, N. W., \& Lawrence, M. (2007). Self-determination and students transition planning knowledge and skills: Predicting involvement. Exceptionality, 15(1), 31-44. 
[30] Zhang, D., \& Law, B. H. (2005). Self-determination as a dropout prevention strategy. Journal of At-Risk Issues, 11, 25-31.
[31] Zheng, C., Gaumer-Erickson, A. S., Kingston, N., \& Noonan, P. M. (2014). The relationship among self-determination, self-concept, and academic achievement for students with learning disabilities. Journal of Learning Disabilities, 47, 462-474. 